\title{
MAGICUS CLOCK
}

\author{
Geethu Issac $^{1}$, Veena Thomas ${ }^{2}$, Geena P George ${ }^{3}$, Rufeena Abu ${ }^{4}$, Shainy Peter ${ }^{5}$ \\ ${ }^{1,2,3,4}$ B.Tech student, ${ }^{5}$ Assistant Professor, ECE, MBITS, Nellimattom, Kerala, India
}

\begin{abstract}
From the world famous series-Harry Potter, written by the British author Miss J.K Rowling, we do come across a 'magical clock'-one of the curious Weasley house holding. Inspired from the same, the magical clock that we have desired to create is a repurposed grandfather clock, modified with gearing that allows four hands to rotate 360 degrees. Faces or clock hands indicate people, with locations instead of times. Then the clock is attached with a microcontroller that would watch for updates on and turn the hands appropriately. This project requires zigbee modules which transmit different signal to be placed on different location of the building, another zigbee module which can be used as a hand set for a person to be tracked and also there is a server system having zigbee module, PIC and stepper motor which receives the signal from handset and move the needle of clock accordingly with the help of stepper motor.
\end{abstract}

Keywords: PIC- Peripheral Inter phase Controller, IC.

\section{INTRODUCTION}

The main objective of our project is to track people and display their location on the dial of a clock. The needles of the clock will represent people and different sectors of the clock will represent different location. Our model will track a single person and identifies three locations.

This is done with the help of programmed PIC [1] microcontrollers, zigbee [2] modules and stepper motors [3]. This project requires zigbee modules which transmit different signal to be placed on different location of the building, another zigbee module which can be used as a hand set for a person to be tracked and also there is a server system having zigbee module, PIC and stepper motor which receives the signal from handset and move the needle of clock accordingly with the help of stepper motor.

Our device can be used as a gadget at home, offices and other busy institutions. With this anybody can know the position of a person without difficulty

\section{SYSTEM DESCRIPTIPON}

\subsection{Existing System}

In this system location of a person in a large building should be tracked manually .It requires lot of time to search for a single person in each and every room of a building. It is less efficient and has loss of energy.

\subsection{Proposed System}

In this system location can be easily tracked out by just looking in a clock. It requires fewer fractions of seconds to track a person on large building. It is highly efficient and has no loss of human energy.

\section{BLOCK DIAGRAM OF MAGICUS CLOCK}

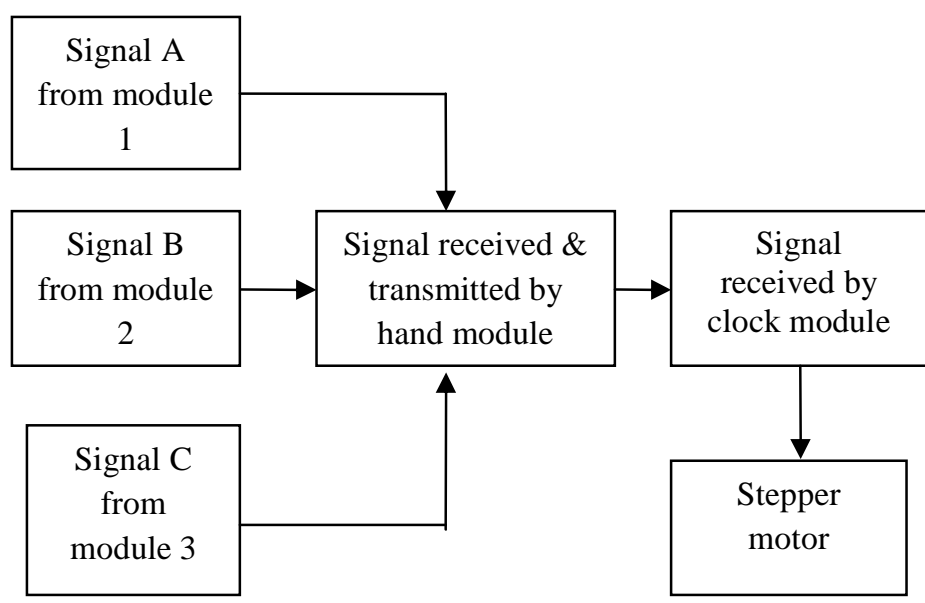

Chart -1: System block diagram

In Magicus Clock five modules are used, each module contains a programmed PIC microcontroller and a zigbee module. Three modules are kept at three rooms via A, B, C. One module is kept at hand set, which is mobile and the fifth module is attached with the clock dial. The three stationary modules kept at three different rooms shall continuously transmit signals A, B, C. When the hand module is at near proximity to any one of them, it receives the signal and retransmits the signal to the clock module. The microcontroller in the clock module causes, the stepper motor to increment according to the signal received. For example, if 
the signal received is $\mathrm{A}$, the motor makes 400 steps, thus causing the clock needle attached to point to location $\mathrm{A}$ on the clock dial \& similarly if $\mathrm{B} / \mathrm{C}$ is received, the motor will takes $800 / 1200$ steps respectively and the needle will move accordingly.

In the clock dial, positions of $\mathrm{A}, \mathrm{B}, \mathrm{C} \&$ home position are arranged according to the steps of stepper motor i.e.; first home position after that $\mathrm{A}$ then $\mathrm{B}$ and last $\mathrm{C}$. In hand set and server $\mathrm{A}, \mathrm{B} \& \mathrm{C}$ signal will not interfere each other since the destination address of $\mathrm{A}, \mathrm{B} \& \mathrm{C}$ is the address of hand set and the destination of hand set is of server. This A,B,C zigbee modules are only for transmitting, hand set is for both transmitting and receiving and zigbee module in server is for receiving .

\section{SOFTWARE DESCRIPTION}

\subsection{Keil}

The Keil IDE is a user-friendly software suite to develop your ' $c$ ' code and assembly language and test the same in a virtual 8051 environment. The main feature of the Keil is that it allows C programming to adapt to the 8051 environment quickly. It offers the designer a device database of MCS-51 family form which the target device of interest can be chosen. The micro vision IDE sets the compiler, assembler, linker, and memory options for the designer. The suite comes with numerous example programs to assist the designer to start his project. With the virtual environment, the available on-chip resources of the microcontroller chosen can be seen working on the PC screen. The simulation window facilitates very realistic simulation of both CPU and embedded peripherals and displays the interaction of the microcontrollers with external peripherals, although the simulation time, it helps to save the bugs and project failure in the long run.

\subsection{Proteus: Simulation Software}

Proteus is circuit simulation software. Proteus consists of two major software parts. They are ISIS and ARES.ISIS is a simulation package where as ARES is a PCB making package. The proteus Design suite is wholly unique in offering the ability to co-simulate both high and low level microcontroller codes in the context of a mixed-mode SPICE circuit simulation. If one person designs both the hardware and the software then that person benefits as the hardware design may be changed just as easily as software design. In larger organizations where the two roles are separated, the software designers can begin work as soon as the schematic is completed.

Proteus VSM contains everything we need to develop, test and virtually prototype our embedded system designs based around Microchip Technologies.

\section{CIRCUIT DIAGRAM DESCRIPTION}

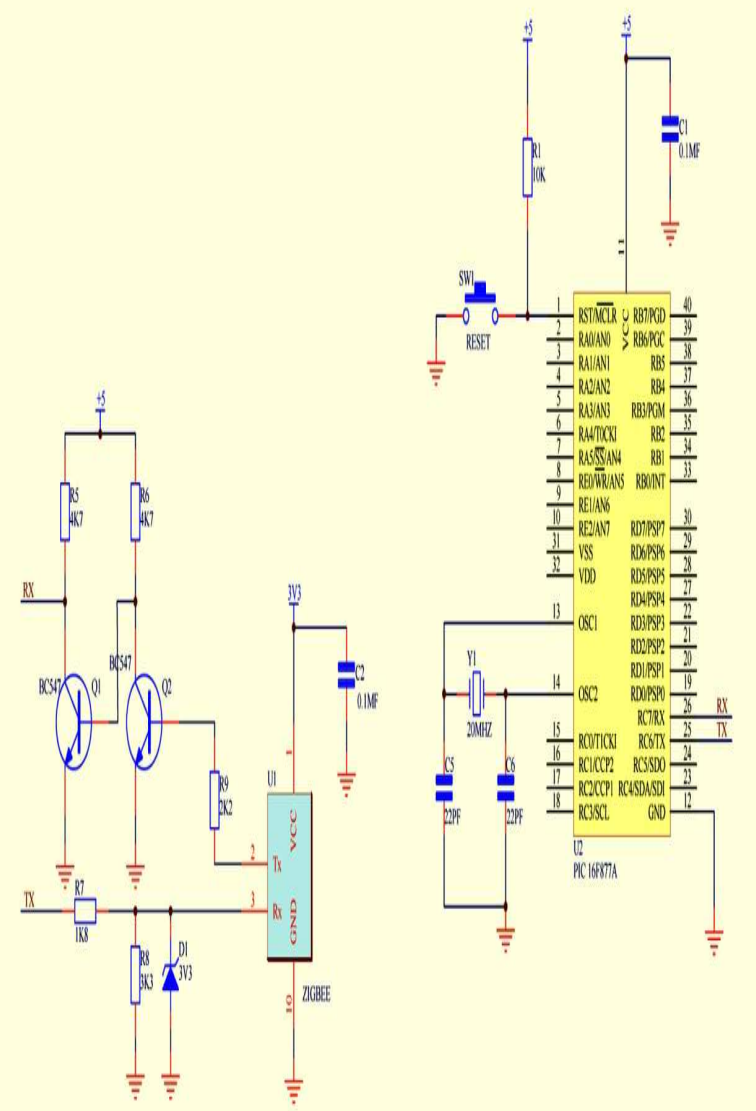

Fig -1: Circuit diagram 
The hardware section consist of five units, they are three stationary Zigbee sections which can be placed in three different locations, one hand set which is mobile that can be hold by person whose location has to be detected, and then a clock section circuitry. The internal circuits can be divided in to three sections; they are power supply circuit, PIC and its associated circuit, and Zigbee section.

\subsection{Power Supply Circuit}

Since PIC, Zigbee, and stepper require $5 \mathrm{~V}, 3.3 \mathrm{~V}, 12 \mathrm{~V}$ respectively, the circuit is arranged in such a way that the above three voltages are always available. For this the circuit mainly consists of two regulator ICs, LM7805 and LM317. Both are three pin ICs, here LM7805 provide a constant 5V output and LM317 can give output voltage between $5 \mathrm{~V}$ and $30 \mathrm{v}$ by varying its associated resistor according to the relation, Vout $=1.25[1+[R 2 / R 1]]$, (Vout can be varied by changing $\mathrm{R} 2)$.

In this circuit a number of capacitors are also included in order to filter out the ripples present in the power supply. The value of capacitors used depends on the frequencies of the ripple percent, according to the relation $\Delta \mathrm{V}=\mathrm{I} / 2 \mathrm{RC}$.If ripple frequency is high value of capacitor used is high. If ripple frequency is high the value of capacitor used is low.

To the circuit a $12 \mathrm{~V}$ supply is given using a two pin switch which is then half wave rectified by a diode, which connected in such a way that it will conduct when positive voltage is applied to its anode. Its output provide $12 \mathrm{~V}$ rectified supply whose small frequency ripples are removed by using high frequency capacitor $\mathrm{C} 7$, and can be used as stepper input. The above voltage is then given to the 1st pin of voltage regulator LM7805 it then regulate the $12 \mathrm{Vsupplt}$ in to $5 \mathrm{~V}$ and available at the 2nd pin, after capacitors $\mathrm{C} 8$ and $\mathrm{C} 3$ ripple free $5 \mathrm{~V}$ supply is available for PIC. This voltage is then given to the second regulator LM317's3rd pin. Input $5 \mathrm{~V}$ is converted to 3.3 Vby varying resistor R2 and ripples are removed using capacitors C9 and C4, then supply for Zigbee is also available.

\subsection{PIC and its Associated Circuit}

In this circuit we used PIC16F877A, a 40 pin IC. For providing external clock input, a $20 \mathrm{MHz}$ crystal oscillator is connected between pins $13 \& 14$ with two capacitor combination C5 and C6 for stabilization. Here we provided power on reset at the pin 1 with the help of a switch SW i.e., a $5 \mathrm{~V}$ supply is always given to the pin 1 and when the reset button is pressed voltage get grounded and reset occurred.PIC need DC 5V supply and it is given with the help of a capacitor $\mathrm{C} 1$, in order to remove the $\mathrm{AC}$ component. A ground is provided at pin 12.During serial communication data is received at the pin 23 and transmitted through pin 25 by the support of USART.

\subsection{Zigbee Section}

This section consists of Zigbee and its receiving transmitting sections. Zigbee operate at the DC supply voltage of $3.3 \mathrm{~V}$ and it is provided at $1^{\text {st }}$ pin with the help of capacitor C2.ground is applied to pin 10. When the receiver section of Zigbee receive data from PIC a $5 \mathrm{~V}$ data is obtained so in order to convert it to a $3.3 \mathrm{~V}$ data a voltage regulator circuit is used which consist of a zener diode whose output is a $3.3 \mathrm{~V}$ and it is then given to the receiver pin of Zigbee. At the transmitter section the low voltage Zigbee output is boosted to $5 \mathrm{~V}$ by using an amplifier circuit. The main components of this circuit are two NPN transistors Q1 andQ2 they are supplied with $5 \mathrm{~V}$ through resistors $\mathrm{R} 3$ and $\mathrm{R} 2$. When a $3.3 \mathrm{~V}$ need to be transmitted it appear as a logic 1 at the transistor base of Q2, which then get turn one and the supply get grounded. As a result Q1 is turned off since the collector of Q2 is connected to the base of Q1, then $5 \mathrm{v}$ supply available at the transmitter, in this way a high level data is transmitted. When a low voltage data wants to be transmitted it appears as a logic 0 and Q2 get turned off as a result Q1 is turned on then supply grounded through the emitter of q1,low voltage at the transmitter.

\section{HARDWARE DESCRIPTION}

The main components used in our project are PIC, Zigbee, and Stepper motor.

\subsection{PIC}

The PIC (Peripheral Inter phase Controller) here we used is IC $16 \mathrm{~F} 877 \mathrm{~A}$,in this specification 16 represents core size, $\mathrm{F}$ for flash memory, 77 represents specific model number and $\mathrm{A}$ for advanced. It is a 40 pin IC operating at a speed of $20 \mathrm{MHz}$.It have hardware architecture i.e. separate memory space and availability of buses for both program and memory. The main internal features of PIC [5] are, it needs only 5V DC power supply and have power on reset.PIC have built in oscillators and interrupt capability. Have three timers, in this Timer 0 and Timer 2 are eight bit timers Timer 1 is a 16 bit timer.PIC support serial mode data communication, for this it provided with USART-Universal Synchronous and Asynchronous Reception and Transmit ion., synchronous means depends on clock and asynchronous means does not depends on clock. USART transmit data as packets of eight bit data, along with eight bit data one start and stop bits are also transmitted. The start bit is represented by a low signal and stop bit by a high signal.

It is a low power, high speed, low cost, widely available IC hence it is commonly used.

\subsection{Zigbee}

The Zigbee used is IC 4214A, it is a 20 pin IC and based on IEEE 802 standards. The main feature of Zigbee is that, it creates a personal area network built from small, low power 
digital radios[4].The maximum voltage required for Zigbee is only $3.3 \mathrm{~V}$ and operates at a $250 \mathrm{~Kb} / \mathrm{s}$.

Zigbee uses serial mode of data communication, transfer data as a packets of eight bit along with one start and stop bits, the start bit is represented by a low signal and stop bit by high signal when no data is transferred signal is always high. The transmitted data also contain both source and destination addresses, which helps the transmitting and receiving units to identify their destination or source respectively.

Zigbee used in applications that require low data rate, long battery life and secure network. Since it is simpler and less expensive than other WPANs, such as Bluetooth or Wi-Fi it is widely used in wireless applications.

\subsection{Stepper Motor}

It is a brushless DC motor that divides a full rotation into a number of equal steps and needs only $12 \mathrm{~V}$ supply. A stepper motor commonly has a permanent magnet rotor surrounded by a stator. Most common have four stator windings that are paired with a center taped common, this is commonly referred as four-phase or unipolar stepper motor. Center tap allows a change of current direction in each two coils when a winding is grounded, there by resulting in a polarity change of the stator and change in the direction of rotation in clockwise or anticlockwise directions. Each step movement of motor is controlled by basic magnetic theory i.e. like poles repels and opposite poles attract.

How much movement is associated with a single step depends on the internal construction of the motor and it is defined in Step angle. Step angle is the minimum degree of rotation associated with a single step. Here we used a stepper whose one step is equal to 0.225 degrees, and then total steps required for completing 360 degrees are 1600 steps.

\section{PCB LAYOUT}

7.1 Layout of the Hand \& Stationary module

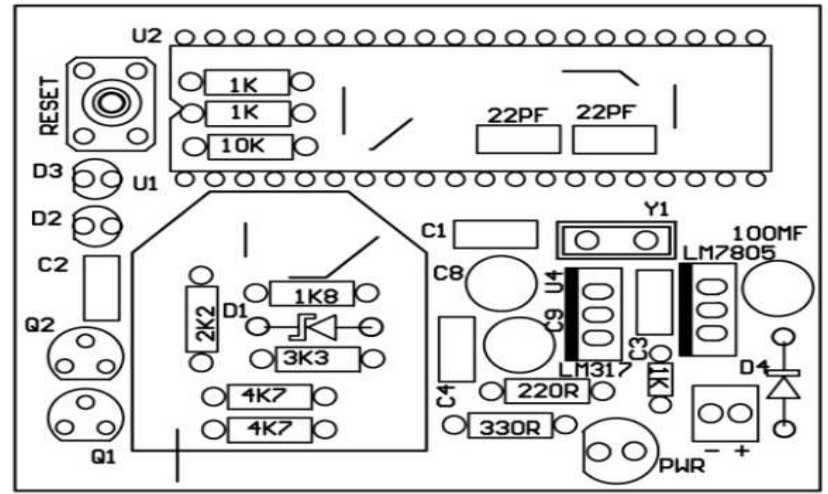

Fig-2:Top view

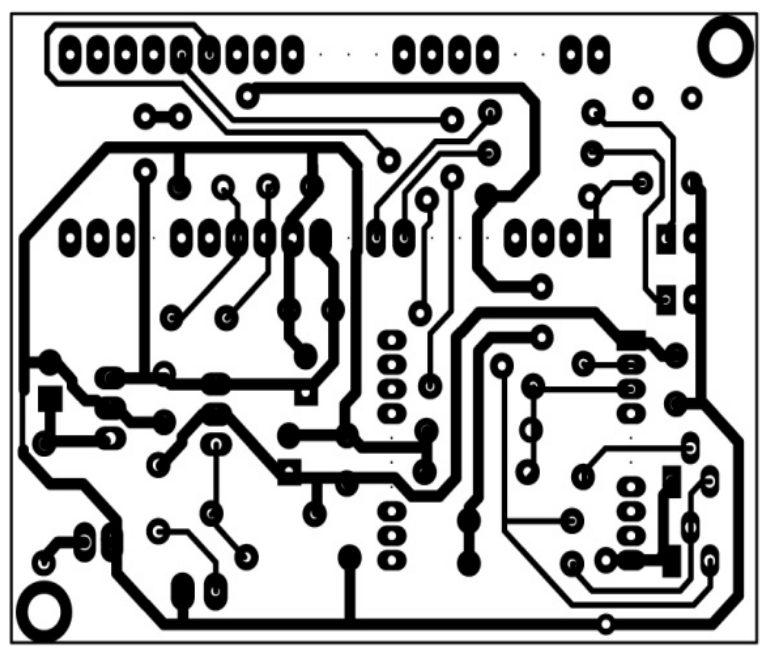

Fig-3: Bottom view

\subsection{Layout of Clock Module}

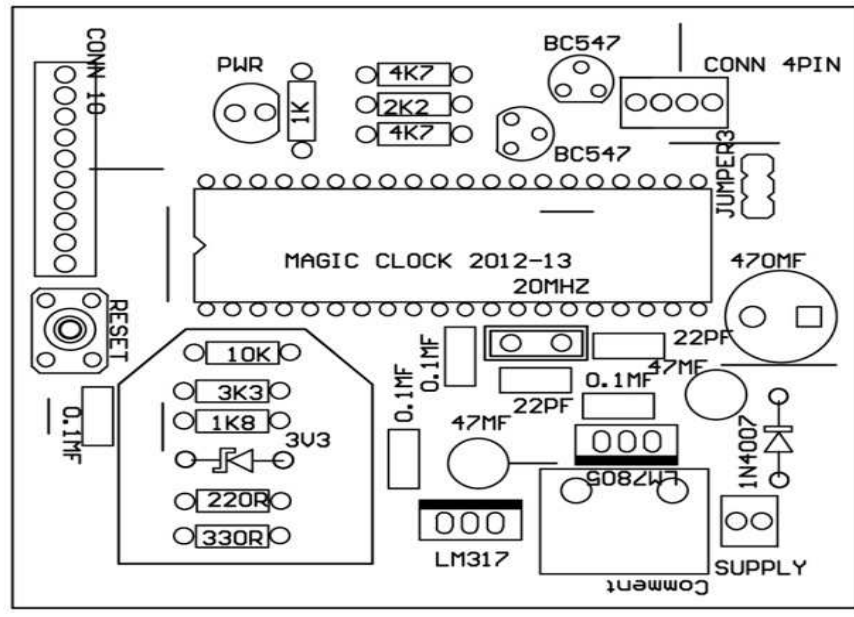

Fig-4: Top view

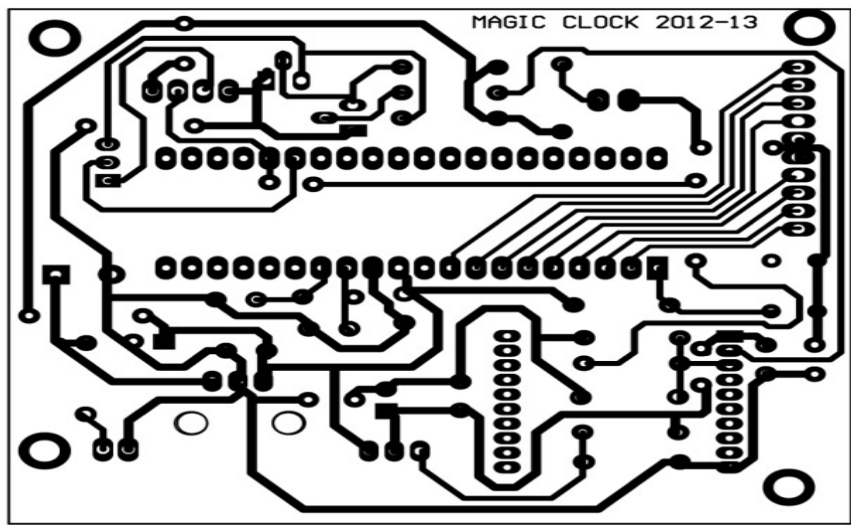

Fig-5: Bottom view 


\section{CONCLUSIONS}

The project "MAGICUS CLOCK" is completed successfully with the use of Zigbee modules, programmed PIC microcontroller, stepper motor and other circuit components, we were successfully able to track the position of a person at three locations at a maximum distance of $30 \mathrm{~m}$ in a building. Our device can be used as a gadget at home, offices and other busy institutions. With this anybody can know the position of a person without difficulty. This requires little expense when compared with other tracking devices and is user friendly.

\section{ACKNOWLEDGEMENTS}

First and the foremost, we thank the ALMIGHTY GOD who gave us the inner strength, resource and ability to complete our work successfully, without which all our efforts would have been in vain.

We express sincere gratitude to our principal, Dr.M.M. Paulose for providing us all help to accomplish our mini project. We stand grateful to our beloved Prof. Johny Joseph, Head of the Department of Electronics and communication engineering, for his valuable advice and motivation. Also we express our heartfelt thanks to our project coordinators Asst.Prof. Jinto Mathew\& Asst.Prof.Shainy Peter for their helpful feedback and timely assistance throughout our work. We also express our sincere thanks to all the staff members of Electronics \& Communication Engineering Department for their help and encouragement. We thank all our friends who have helped with their prayer and encouragement.

Once again, we thank all those who have helped directly and indirectly to complete our work.

\section{REFERENCES}

[1]..PIC Microcontroller \& Embedded System-Muhammad Ali mazidi, Rolin D McKinley \&Danny Causey

[2]. Zigbee wireless networking by Drew Gislason

[3]. The 8051 Microcontroller and Embedded Systems

[4]. http://www.digi.com/pdf/ds_xbeemultipointmodules.pdf

[5]. http://www.wvshare.com/datasheet_html/PIC16F877A-

PDF.html

\section{BIOGRAPHIES}

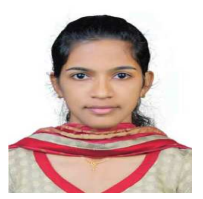

Geethu Issac, Pursuing B.Tech degree in Electronics And Communication from Mar Baselios Institute Of Technology And Science, Nellimattom, Ernakulam Dst, Kerala, India.

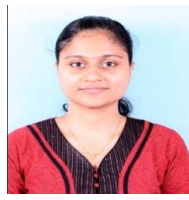

Veena Thomas, Pursuing B.Tech degree in Electronics And Communication from Mar Baselios Institute Of Technology And Science, Nellimattom, Ernakulam Dst, Kerala, India.

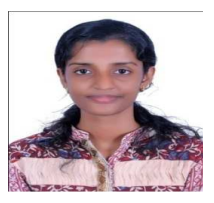

Geena P George, Pursuing B.Tech degree in Electronics And Communication from Mar Baselios Institute Of Technology And Science, Nellimattom, Ernakulam Dst, Kerala, India.

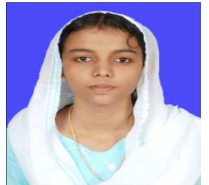

Rufeena Abu, Pursuing B.Tech degree in Electronics And Communication from Mar Baselios Institute Of Technology And Science, Nellimattom, Ernakulam Dst, Kerala, India.

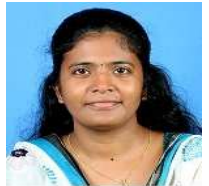

Shainy Peter, Currently working as Assistant Professor in Electronics And Communication department in Mar Baselios Institute of Technlogy \&Science, Nellimattom, Kerala since 2011 July. Received BTech degree in ECE from Sree Narayana Gurukulam College of Engineering, Kadayirippu, Kerala in the year 2008,under MG University. Received MTech degree in Microwave Electronics from Cochin University of Science and Technology, Kalammassery, Cochin, Kerala in 2011. 